\title{
Assessing Agri-Environmental Indicators and Pollution Impacts on Environmental Performance Index and Agri-Economic Indicators in EU and ME countries: A Bayesian Network Based Model
}

\author{
Ali Firoozzare \\ Ferdowsi University of Mashhad \\ somayeh Naghavi ( $\square$ somnaghavi@ujiroft.ac.ir) \\ University of Jiroft https://orcid.org/0000-0001-7380-9554
}

\section{Research Article}

Keywords: Agri-environmental-economic indicators, Agriculture area certified organic, Agricultural value added, Bayesian Network, Environmental Performance Index, Land productivity

Posted Date: April 6th, 2021

DOI: https://doi.org/10.21203/rs.3.rs-342686/v1

License: () (1) This work is licensed under a Creative Commons Attribution 4.0 International License. Read Full License 


\section{Abstract}

Agricultural sector has a key role in relation to poverty reduction and improving food security.One of important challenges in the agriculture sector is to feed population that is increasing in the world. Agriculture has significant and negative impacts on the environment and earth ecosystems. The agricultural sector growth has made pollution and pollution has restricted increasing production in agricultural. Climate change has led researchers to pay close attention to environmental performance. Bayesian networks are relatively well recognized to be an advantageous method for different types of environmental model. This study was designed a Bayesian network model to investigate the relation between agri-economic-environmental indicators and Environmental performance Index in the EU countries compared to Middle East countries, in 2018. we showed relations between variables of model based on expert interview and previous researches. The results indicated land productivity is directly affected by node Agriculture area certified organic. We predicted with developing Agriculture area certified organic and conservation agricultural area, and productivity can be increased in EU Countries. Also, our findings showed with decreasing $\mathrm{N} 2 \mathrm{O}$ and $\mathrm{CH} 4$ emissions indicators, increased Enivironmental performance index in EU countries and decreasesd in Middle East countries. Terefore, EU countries is improved agricultural practices and pesticides and fertilizer, But ME countries have not been successful in improving the environmental performance index and sustainable development objectives. Modelling of agri-environmental indicators can help to policymakers about the changes of agro-ecosystem and can use for international reviews.

\section{Introduction}

The COVID-19 pandemic is threated human health and vulnerabilities the food security in the world (United Nations, 2020). Agricultural sector has a key role in relation to poverty reduction and improving food security. The Growthing of agricultural productions has made pollution and pollution has restricted increasing production in agricultural sector (Li et al. 2019). Therefore,Agriculture sector has an important role in sustainability issues (Pretty, 2008; UN, 2015). Increasing the food production causes the chemical pesticides and fertilizers use increases in agricultural sector (Chakraborty et al., 2014).Pesticides and fertilizers use threaten human health and environmental.Therefore, Sustainable agriculture became an important issue (Punith Kumar and Indira, 2017).

Population growth and food production in agrcultural sector are lead to pressure on water resources and environmental (Liu et al., 2017; Falkenmark et al., 1989; Alcamo et al., 2000; Verosmarti et al.,2000). Therefore, the environmental problems (Pretty, 2008) and Avoiding use of agrochemicals, in regard to sustainable development is a major issue (Sulewski et al, 2018). Organic farming is an agricultural method that is in line with the objectives of sustainable development, improving food security and reducing the agrichemicals use (WHO \& Food and agricultural Organization,2015). Organic farming can increase the natural fertility and potential of agricultural soil production, especially in communities at food poverty. Muller et al. (2017) showed organic agricultural decreases $\mathrm{N}$-surplus and chemiacal pesticieds use.

Agriculture has significant and negative impacts on the environment and earth ecosystems. Therefore, to investigate agri-environmental indicators, environmental dimension should be considered.While the agricultural sector management is vital to improving life, if it don't managed well, there is a risk of environmental damage. Improving farming approaches can help to the environment protection and public health (FAo of the United Nations, 2011). Agriculture sector growth has considerable effect on the environment, therefore protect of environment quality is a major issue in sustainable development. In this regard, the environmental performance index (EPI) considred two major goals of environmental protection, including decreasing environmental health and ecosystem vitality (Shahabadi et al, 2017; Zarandi Motasadi and Bebaran, 2009). The environmental performance index is a very important indicator that identifies goals to achieve environmental efficiency and measures the current position of each of the components of this index and evaluates the position of each country in achieving the desired goals. The environmental performance index also provides an effective and valid tool to guide policymakers in the field of environment. This index is one of the major indicators of the development of countries.

There are few studies on the relation between agri-economic-environmental and EPI indicators together using Bayesian networks. Grotkiewicz (2017) applied Bayesian network to investigate the relation between sustainable agricultural. Carpani \& Giupponi (2010) designed Bayesian network to investigate of agricultural and environmental indicators. Viikari et al (2007) evaluated agri-environmental indicators at national level. Mohammadian et al. (2020) investigated economic and environmental effects of crop diversification in mahidasht plain of iran. Russell et al (2018) investigated spatial assessment of environmental indicators in Kazakhstan. Ali shah and Longsheng (2020) investigated new environmental performance inde for measuring environmental performance in major sectora in Pakistan. Results showed all the sectors don,t have desire environmental performance.

Volkov et al (2020) investigated economic and environmental erformance of the Agricultural Sectors of the Selected EU Countries. The results showed that the new EU member states have higher performance compared to the old member states. Dkhili (2019) investigated the relation between environmental performance index and economic growth in Middle East and north africa countries. Widatat et al (2019) exmained the relation between environmental performance index and Agricultural Productivity. Jafari samimi et al. (2010) in their study, investigated the relation between economic growth and environmental performance index in the developing countries. The results showed a positive relation between environmental performance index and economic growth. Safarelizadeh et al. (2017) investigated the relative of the middle East in terms of sustainable Development indices. Results indicated that more than $60 \%$ of the Middle East countries had a moderate performance level in regard to sustainable development indicators from 2009 to 2012. Kaikkonen et al (2020) applied BN model for environmental assessment across a range of ecosystem types and scales. Batary et al (2015) examined the role agricultural-environmental programs in protection and environmental management.

Considering thereview literature and the importance of environmental management and countries' attention to improving environmental performance, so far a study is not done to compare the prediction of the impacts of environmental indicators on agricultural economic indicators and also the impact of pollution on environmental performance improvement indicators in the Middle East and the Union Europe. The environmental situation of countries and its changes is one of the important issues of the new era. In the Middle East, there is a growing emphasis on investigating the institutional requirements of 
technological modernization, expanding local energy consumption, and paying attention to pollution from the activities of governments and non-state actors (Maleki, 2018).

Assessing the risks from agriculture to the environment is a major problem. Common Agricultural Policy (CAP) in regard to agri-environment policy was considered in the European Union in in the mid-1980s for declining environmental standards. Agri-environment schemes (AES) are provides for agricultural management (Batary, 2015).Sustainable development is a major aim for the European Union in line with environment protection and social justice (Radermacher, 2009). Also, the Middle East countries, despite their many natural gifts, have faced many challenges in the path of sustainable development.

In this study, we try to investigate and answer what is the relation between agri-economical and environmental indicators in the EU countries compared to Middle East countries? and What is the impact of agriculture pollution on the environment performance index? so that policymakers and researchers can target the most important impacts? And Which countries in the Middle East and the European Union have done better to improve environmental performance? Therefore, we used Bayesian network model to investigate ageneral review of the agri-environmental indicators and pollution impact on agrieconomics indicators in the Middle East and EU. Also, we assessed factors affecting environmental performance and provide tips used for decision makers in the Middle East and EU in 2018 year.Bayesian network is a probabilistic model that shows the relation between various variables and can combine agricultural-economical and environmental indicators. Modelling of agri-environmental indicators can help to policymakers about the changes of agroecosystem and can use for international reviews.

\section{Materials And Methods}

\section{Data description and sources}

The major objective of our study is the assessment of relation between agri-economic- environment indicators and EPI in the selected countries, EU members and Middle East using Bayesian Network modelling. In figure 1 have been introduced agri-environmental indicators to represent the relations between agriculture and the environment. Also, A summary description of the methodology is shown in figure2.

In figure 3 is shown Geographical location of the study region, Europe union and and Middle East conuntries.

In figure 4-5, were mapped status of countries based,Consumption of Nutrient potash K2O, Consumption of Nutrient Nitrogen N and Consumption of Nutrient phosphate P2O5 and Agriculture area certified organic, respectively using GIS software.

In 2018, 69 million hectares of land in the world were under organic farming. In the EU in $2017,7 \%$ of the total land is under organic farming. The growth of organic production by $70 \%$ over the past ten years indicates the importance of organic agricultural (EU,2019).

In 2018, in Eu countries 13.4 million hectares of agricultural lands were under organic agricultural Fig 1 shows area under organic farming is concentrated in Spain, Germany, Italy, France. Also, right side of map, Fig 1, can be seen the highest level of Agriculture area certified organic is concentrated in Egypt.

Use of fertilizers in agriculture is the key source for greenhouse gas emissions from agricultural soils. Mineral fertilizers, such as nitrogen ( $\mathrm{N}$ ) and phosphorus (P), are widely used in agriculture to optimize production. A surplus of nitrogen and phosphorus can lead to environmental pollution. In 2018 , 10.2 million tons of nitrogen fertilizer was used in EU agriculture, a slight increase of $1.9 \%$ since 2008 (Eurostate, 2018).

Based on the analysis from FAOSTAT (2017), between considered EU countries (left side of map) the highest level of Consumption of Nutrient Nitrogen N, Consumption of Nutrient potash K2O, and Nutrient phosphate P2O5 per hectare are occurred in Slovakia, Lithuania, Latvia. Also, between considered Middle East countries, the highest level of Consumption of these Mineral fertilizers are occurred in Egypt and Jordan.

\section{Environmental Performance Index}

The environmental performance index (EPI) is a method of ranking and scoring the environmental performance a country toward the sustainable development objectives (Shahabadi et al, 2017). In this regard, the environmental performance index (EPI) considred two major goals of environmental protection, including decreasing environmental health and ecosystem vitality (Shahabadi et al, 2017; Zarandi Motasadi and Bebaran, 2009). In figure 6 is shown components of Environmental performance index in 2018.

In figures 7 is illustrated EPI Score for selected contries. What has been the performance of countries in the field of prevent environmental degradation?

As is shown in figures 7, in 2018, in Eu Countries, France has more EPI score other counties and in Middle East Countries, Israeal has more EPI score other counties. Therefore, These two countries have done better than other countries in preventing environmental degradation.

\section{Bayesian network}

The Bayesian network are probabilistic model (Kaikkonen, 2020) that can be applied to decision making in conditions of uncertainty (Levontin et al, 2011) and represent a set of variables without a clear causal structure (Carriger, 2021). The objective of the Bayesian network is to represent the independent relationships between effective variables and the uncertainty associated with these variables (Arnaldo Valdés, 2018). The Bayesian network provides a framework for representing the uncertainty of variables in the network and consists of three parts: nodes, links and conditional probability tables. The nodes are variables, and links represent causal relationships between nodes (Mamitimin et al. 2015). 
The Bayesian network consists of three steps: (1) identify the nodes 2) create link between the nodes; 3 ) creat probabilities relation to each node (Chai et al, 2020). In present research was employed software package Netica for modelling Bayesian network.

The Bayesian network that we developed is based on major variables and links between different variables were identified through expert knowledge.

The conditional probability is based on Bayesian theorem, which is as follows: see formula 1 in the supplementary files section.

Where A and B are the two random occurrences (Mamitimin et al. 2015), " " shows the probability of occurrences $i$, and " " shows the probability of occurrences $B$ (Mamitimin et al. 2015). " " is the conditional probability of occurrences A when occurrences $b$ is occured" (Mamitimin et al. 2015, Pearl 1988, Koski and Noble 2011, Blitzstein and Hwang 2014).

\section{Results And Discussion}

Discrete values are required in the Bayesian network.For Discretization of constant values Grotkiewicz, 2017) can be used Analytical methods. In this study we use two-step cluster approach for grouping variables.

In this study, we selected 14 variables as representative agri-economic and agri-environmental indicators to create Bayesian network structure in EU countries and 12 variables in Middle East. Data was obtained from the FAOSTAT in 2018 year. It should be noted we designed various Bayesian network models using multiscenario to investigate the relation between indicators. The results are presented as follows. The Bayesian network contained 14 nodes and 28 links in EU countries and 12 nodes and 23 links in Middle East countries. In Table 1 can be seen variables included in the final Bayesian network for EU countries.

Economic indicators: Economic indicators are one of the model indicators that their changes are examined by considering environmental scenarios. We choose 3 economic indicators, Agricultural value added, Labor productivity and Land productivity (Grotkiwicz, 2017) in EU and Middle East countries.

Agri- Environmental indicators: Agri- Environmental indicators are one other of the model indicators that extracted from FAOSTAT. We choose 11AgriEnvironmental indicators, Agriculture area certified organic, conservation agricultural area, Nutrient nitrogen N, Nutrient potash K2O, Nutrient phosphate P205, Pesticides, Balance per hectare, N2O emissions, CH4 emissions, Livestock units per agricultural land area, Land area equipped for irrigation (FAOSTAT, 2018) in EU and10 Agri-Environmental indicators, Agriculture area certified organic, Nutrient nitrogen N, Nutrient potash K2O, Nutrient phosphate P205, Pesticides, N2O emissions, CH4 emissions, Livestock units per agricultural land area, Land area equipped for irrigation (FAOSTAT, 2018) in Middle East countries.

In this study, land productivity and labor productivity are obtained based on the following formula:

\section{See formulas 2 and 3 in the supplementary files.}

Where, is Gross Domestic Production in Agricultural (USD) in the EU and ME countries, is Labor force in agricultural sector in the EU and ME countries, is area of agricultural land (ha) in the EU and ME countries.

In Tables 1-2 are shown variables that we used in the final Bayesian network for EU and ME countries.

Table 1 Variables of the final Bayesian network for EU countries, 2018

\begin{tabular}{|ll|}
\hline Variable (node) & Prior Probability (Node states) \\
\hline Agriculture area certified organic & Low (58.6\%), Medium (20.7\%), High (20.7\%) \\
\hline conservation agricultural area & Low (75.7\%), Medium (10.8\%), High (13.4\%) \\
\hline Nutrient nitrogen N & Low (66.6\%), Medium (11.2\%), High (22.2\%) \\
\hline Nutrient potash K20 & Low (63.6\%), Medium (20\%), High (16.4\%) \\
\hline Nutrient phosphate P205 & Low (72.4\%), Medium (13.9\%), High (13.7\%) \\
\hline Pesticides & Low (46.2\%), Medium (28.7\%), High (25.1\%) \\
\hline Balance per hectare & Low (33.7\%), Medium (44.3\%), High (22\%) \\
\hline Land productivity & Low (39.7\%), Medium (30.2\%), High (30.1\%) \\
\hline N20 emissions & Low (43.6\%), Medium (28.4\%), High (28\%) \\
\hline CH4 emissions & Low (43\%), Medium (29. \%), High (28\%) \\
\hline Agricultural value added & Low (53.4\%), Medium (46.6\%) \\
\hline Livestock units per agricultural land area & Low (82.1\%), Medium (17.9\%) \\
\hline Land area equipped for irrigation & Low (72.4\%), Medium (6.90\%), High (20.7\%) \\
\hline Labor productivity & Low (30\%), Medium (26.7\%), High (26.7\%), Very High (16.7\%) \\
\hline
\end{tabular}


Table 2 Variables of the final Bayesian network for ME countries, 2018

\begin{tabular}{|ll|}
\hline Variable & Definition/Prior Probability \\
\hline Agriculture area certified organic & Low (80\%),High (20\%) \\
\hline Nutrient nitrogen N & Low (65.1\%), Medium (15.4\%), High (19.4\%) \\
\hline Nutrient potash K20 & Low (42.3\%), Medium (26.9\%), High (30.9\%) \\
\hline Nutrient phosphate P2O5 & Low (59.4\%), Medium (26.9\%), High (13.7\%) \\
\hline Pesticides & Low (70.4\%),High (29.6\%) \\
\hline Land productivity & Low (55.4\%),High (44.6\%) \\
\hline N20 emissions & Low (35.7\%), Medium (32.6\%), High (31.8\%) \\
\hline CH4 emissions & Low (34.7\%), Medium (32.7\%), High (32.7\%) \\
\hline Agricultural value added & Low (57.3\%),High (42.7\%) \\
\hline Livestock units per agricultural land area & Low (53.3\%), Medium (46.7\%) \\
\hline Land area equipped for irrigation & Low (73.3\%),High (26.7\%) \\
\hline Labor productivity & Low (68.8\%), Medium (18.8\%), High (12.5\%) \\
\hline
\end{tabular}

In figures 8-9 are illustrated Bayesian network with the probability distribution of variables in the EU and ME countries. The relation between variables is built based on expert interview and literature reviews that can be seen in the figure 8-9.

In this structure, nodes represent variables of Bayesian network model. As shown in figure 1, conservation agricultural area is directly affected by node Agriculture area certified organic. Nutrient nitrogen N, Nutrient potash K2O, Nutrient phosphate P205, Pesticides, Balance per hectare are directly affected by node conservation agricultural area. Also, Agricultural value added is affected by nodes land productivity, Livestock units per agricultural land area and labor productivity. Also in figure 2 is shown, Nutrient nitrogen N, Nutrient potash K2O, Nutrient phosphate P2O5, Pesticides are directly affected by node Agriculture area certified organic. Also, Agricultural value added is affected by nodes land productivity, livestock units per agricultural land area, labor productivity and indirectly by node Agriculture area certified organic.

\section{Scenario Analysis}

The Table 2 shows different Scenarios and posterior probability distribution for predicting agri- environmental indicators impacts on agri-economica indicator in EU and ME countries, in 2018.

\section{Agriculture area certified organic scenario}

In this section, in first, it can be seen the impact of Agriculture area certified organic from environmental aspect. The results are provided in table 3.

Table 3 illustrates that Agriculture area certified organic (Aaco) and conservation agricultural area (Caa) influence on nods, Nutrient nitrogen $\mathrm{N}$, Nutrient potash K2O, Nutrient phosphate P205, Pesticides and Balance per hectare. in the table $3, \ldots$, , are calculated and the results are shown.

As an example, when (Aaco=high, $\mathrm{Caa}=$ high) or (Aaco=high, Caa=medium) or (Aaco=medium, Caa=high) or (Aaco=medium, Caa=medium) or (Aaco=low, Caa=high) or (Aaco=low, Caa=medium) Balance per hectare = high. When (Aaco=high, Caa=low) or (Aaco=medium, Caa=low) or (Aaco=low, Caa=low) Balance per hectare $\mathrm{N}=$ medium. However, Balance per hectare can be high if Agriculture area certified organic be at high, medium and low states and conservation agricultural area be at high state.

Table 3. Results of posterior probability distribution (\%) agri -environmental indicators in EU countries, 2018. 


\begin{tabular}{|c|c|c|c|c|c|c|c|c|c|c|c|c|c|c|c|c|}
\hline Aaco* & Caa* & $\begin{array}{l}\mathrm{P}(\text { Nutrient } \\
\text { nitrogen } \\
\mathrm{N})\end{array}$ & $\begin{array}{l}\mathrm{P}(\text { Nutrient } \\
\text { potash } \\
\mathrm{K} 20)\end{array}$ & $\begin{array}{l}\mathrm{P}(\text { Nutrient } \\
\text { phosphate } \\
\text { P205) }\end{array}$ & Pesticides & $\begin{array}{l}\text { Balance } \\
\text { per } \\
\text { hectare }\end{array}$ & & & & & & & & & & \\
\hline L & $M$ & $\mathrm{H}$ & L & $M$ & $\mathrm{H}$ & L & $M$ & $\mathrm{H}$ & $\mathrm{L}$ & $M$ & $\mathrm{H}$ & L & $M$ & $\mathrm{H}$ & & \\
\hline high & high & $20 \%$ & $20 \%$ & $60 \%$ & $20 \%$ & $20 \%$ & $60 \%$ & $20 \%$ & $20 \%$ & $60 \%$ & $20 \%$ & $20 \%$ & $60 \%$ & $25.3 \%$ & $25.3 \%$ & $49.3 \%$ \\
\hline high & medium & $25 \%$ & $25 \%$ & $50 \%$ & $25 \%$ & $25 \%$ & $50 \%$ & $25 \%$ & $50 \%$ & $25 \%$ & $25 \%$ & $25 \%$ & $50 \%$ & $29.2 \%$ & $29.2 \%$ & $41.6 \%$ \\
\hline high & low & $80.8 \%$ & $7.69 \%$ & $11.5 \%$ & $76.9 \%$ & $19.2 \%$ & $3.85 \%$ & $88.5 \%$ & $7.69 \%$ & $3.85 \%$ & $53.8 \%$ & $30.8 \%$ & $15.4 \%$ & $35.8 \%$ & $49.9 \%$ & $14.3 \%$ \\
\hline medium & high & $20 \%$ & $20 \%$ & $60 \%$ & $20 \%$ & $20 \%$ & $60 \%$ & $20 \%$ & $20 \%$ & $60 \%$ & $20 \%$ & $20 \%$ & $60 \%$ & $25.3 \%$ & $25.3 \%$ & $49.3 \%$ \\
\hline medium & medium & $25 \%$ & $25 \%$ & $50 \%$ & $25 \%$ & $25 \%$ & $50 \%$ & $25 \%$ & $50 \%$ & $25 \%$ & $25 \%$ & $25 \%$ & $50 \%$ & $29.2 \%$ & $29.2 \%$ & $41.7 \%$ \\
\hline low & high & $20 \%$ & $20 \%$ & $60 \%$ & $20 \%$ & $20 \%$ & $60 \%$ & $20 \%$ & $20 \%$ & $60 \%$ & $20 \%$ & $20 \%$ & $60 \%$ & $25.3 \%$ & $25.3 \%$ & $49.3 \%$ \\
\hline low & medium & $25 \%$ & $25 \%$ & $50 \%$ & $25 \%$ & $25 \%$ & $50 \%$ & $25 \%$ & $50 \%$ & $25 \%$ & $25 \%$ & $25 \%$ & $50 \%$ & $29.2 \%$ & $29.2 \%$ & $41.6 \%$ \\
\hline low & low & $80.8 \%$ & $7.69 \%$ & $11.5 \%$ & $76.9 \%$ & $19.2 \%$ & $3.85 \%$ & $88.5 \%$ & $7.69 \%$ & $3.85 \%$ & $53.8 \%$ & $30.8 \%$ & $15.4 \%$ & $35.8 \%$ & $49.9 \%$ & $14.3 \%$ \\
\hline
\end{tabular}

Aaco*, Agriculture area certified organic

Caa*, conservation agricultural area

In following, we provided the results of scenarios analysis in the Middle East countries in 2018.

Table 4. results of posterior probability distribution agri- environmental indicators in Middle East countries,2018.

\begin{tabular}{|c|c|c|c|c|c|c|c|c|c|c|c|}
\hline $\begin{array}{l}\text { Agriculture area } \\
\text { certified organic }\end{array}$ & $\begin{array}{l}P(\text { Nutrient } \\
\text { nitrogen } N)\end{array}$ & $\begin{array}{l}\mathrm{P} \text { (Nutrient } \\
\text { potash K2O) }\end{array}$ & $\begin{array}{l}\text { P(Nutrient } \\
\text { phosphate } \\
\text { P205) }\end{array}$ & Pesticides & & & & & & & \\
\hline L & $M$ & $\mathrm{H}$ & $\mathrm{L}$ & $M$ & $\mathrm{H}$ & $\mathrm{L}$ & $\mathrm{M}$ & $\mathrm{H}$ & $\mathrm{L}$ & M & \\
\hline High & $40 \%$ & $20 \%$ & $40 \%$ & $40 \%$ & $20 \%$ & $40 \%$ & $40 \%$ & $20 \%$ & $40 \%$ & $75 \%$ & $25 \%$ \\
\hline Low & $71.4 \%$ & $14.3 \%$ & $14.3 \%$ & $42.9 \%$ & $28.6 \%$ & $28.6 \%$ & $64.3 \%$ & $28.6 \%$ & $7.14 \%$ & $69.2 \%$ & $30.8 \%$ \\
\hline
\end{tabular}

Table5. Results of posterior probability distribution (\%) economic indicators in EU countries, 2018

\begin{tabular}{|c|c|c|c|c|c|c|}
\hline Aaco & Caa & $\mathrm{P}$ (Land productivity) & $\mathrm{P}($ Agricultural value added $)$ & & & \\
\hline L & M & $\mathrm{H}$ & L & $\mathrm{H}$ & & \\
\hline high & high & $33 \%$ & $33.6 \%$ & $33.4 \%$ & $52.2 \%$ & $47.8 \%$ \\
\hline high & medium & $33.2 \%$ & $33.5 \%$ & $33.3 \%$ & $52.2 \%$ & $47.8 \%$ \\
\hline high & low & $33.3 \%$ & $33.3 \%$ & $33.3 \%$ & $52.3 \%$ & 47.75 \\
\hline medium & high & $33.4 \%$ & $33.3 \%$ & $33.3 \%$ & $52.3 \%$ & $47.7 \%$ \\
\hline medium & medium & $33.4 \%$ & $33.3 \%$ & $33.3 \%$ & $52.3 \%$ & $47.7 \%$ \\
\hline medium & low & $35.9 \%$ & $32 \%$ & $32 \%$ & $52.7 \%$ & $47.3 \%$ \\
\hline low & high & $33.4 \%$ & $33.3 \%$ & $33.3 \%$ & $52.3 \%$ & $47.7 \%$ \\
\hline low & medium & $33.4 \%$ & $33.3 \%$ & $33.3 \%$ & $52.3 \%$ & $47.7 \%$ \\
\hline low & low & $44.8 \%$ & $27.6 \%$ & $27.6 \%$ & $54.2 \%$ & $45.8 \%$ \\
\hline
\end{tabular}

It can be seen in table 5, when (Aaco=high, Caa=high) or (Aaco=high, Caa=medium), Land Productivity= medium and Agricultural value added= low. when (Aaco=high, Caa=high) or (Aaco=medium, Caa=medium) or (Aaco=medium, Caa=low) or (Aaco=low, Caa=high) or (Aaco=low, Caa=medium) or (Aaco=low, Caa=low), Land Productivity= medium and Agricultural value added=low and when (Aaco=low, Caa=low), Land Productivity= low and Agricultural value added= low. When Agriculture area certified organic and conservation agricultural area be at high state in EU countries, Land Productivity is medium with highest probability $33.6 \%$ and when Agriculture area certified organic and conservation agricultural area be at low state in EU countries Agricultural value added and land Productivity at low state with highest probability, $54.2 \%$ and $44.8 \%$. 
The results in table 5 indicate when (Aaco=high or low), Nutrient nitrogen $\mathrm{N}$ is low. Therefore When Agriculture area certified organic be at low state in Middle East countries, Nutrient nitrogen $\mathrm{N}$ are at low state with highest probability, $71.4 \%$.

As shown table 6, when (Aaco=high), Land Productivity= low or high and Agricultural value added=low. when (Aaco=low), Land Productivity= low and Agricultural value added= low. When Agriculture area certified organic be at low state in Middle East countries, Land Productivity and Agricultural value added are at low state with highest probability, $56.8 \%$ and $57.5 \%$.

\begin{tabular}{|c|c|c|c|c|}
\hline Agriculture area certified organic & P(Land Productivity) & P(Agricultural value added) & & \\
\hline Low & High & Low & High & \\
\hline High & $50 \%$ & $50 \%$ & $56.6 \%$ & $43.4 \%$ \\
\hline Low & $56.8 \%$ & $43.2 \%$ & $57.5 \%$ & $42.5 \%$ \\
\hline
\end{tabular}

Table 6. results of posterior probability distribution (\%) economic indicators in East Middle countries, 2017.

In following of this study, is shown the results of the impact increasing Balance per hectare on agri-economic-environmental .

The results of analysis in the table 7 indicate, if (Balance per hectare =high), N2O emissions is high. When (Balance per hectare =medium or, low) N2O emissions = low. However, N2O emissions can be low if Balance per hectare be at medium state.

Table 7. Results of posterior probability distribution agri -environmental indicators in EU countries, 2018

\begin{tabular}{|c|c|c|c|c|c|c|}
\hline Balance per hectare & P(N2O emissions) & $\mathrm{P}(\mathrm{CH} 4$ emissions $)$ & & & & \\
\hline L & $M$ & $\mathrm{H}$ & $\mathrm{L}$ & M & $\mathrm{H}$ & \\
\hline high & $33 \%$ & $33.5 \%$ & $33.5 \%$ & $33 \%$ & $33.5 \%$ & $33.5 \%$ \\
\hline medium & $48.8 \%$ & $26 \%$ & $25.25 \%$ & $47.3 \%$ & $27.5 \%$ & $25.2 \%$ \\
\hline low & $43.7 \%$ & $28.1 \%$ & $28.1 \%$ & $43.7 \%$ & $28.1 \%$ & $28.1 \%$ \\
\hline
\end{tabular}

The results of table 8 show, when (Balance per hectare =high), Land Productivity= medium and Agricultural value added=low. When (Balance per hectare =medium), Land Productivity= low and Agricultural value added=low. When (Balance per hectare =low), Land Productivity= low and Agricultural value added= low. However, Agricultural value added can be low if Balance per hectare be at medium state. Also, Land Productivity can be low if Balance per hectare be at medium state.

Table 8. Results of posterior probability distribution economic indicators in EU countries, 2018

\begin{tabular}{|c|c|c|c|c|c|}
\hline Balance per hectare & P(Land productivity) & $\mathrm{P}$ (Agricultural value added) & & & \\
\hline L & M & $\mathrm{H}$ & $\mathrm{L}$ & $\mathrm{H}$ & \\
\hline high & $33.2 \%$ & $33.5 \%$ & $33.3 \%$ & $52.2 \%$ & $47.8 \%$ \\
\hline medium & $43 \%$ & $28.5 \%$ & $28.5 \%$ & $53.9 \%$ & $46.1 \%$ \\
\hline low & $39.7 \%$ & $30.2 \%$ & $30.2 \%$ & $53.4 \%$ & $46.6 \%$ \\
\hline
\end{tabular}

\section{Sensitivity analysis}

For validating Bayesian network use both techniques: 1) Interview experts 2) sensitivity analysis (Korb and Nicholson ,2011; Sule et al, 2018). In present study, we used both techniques.In figures 11-12 are shown the results of the sensitivity analysis of BN for agricultural value added and Land productivity in EU countries. In this study we applied Netica software for sensitivity analysis. The variance reduction is used to rank the variables from highest to lowest important in terms of impacts on the target node. Larger variance reduction values indicate highest impact. In figure 11, target node is Agricultural value added in EU countries.

As shown in figures 10-11, agricultural value added is target variable. The sensitivity analysis indicated that the labor productivity variable is the most influential variables in EU and ME countries.

As shown in figure 11, land productivity is target variable. The results showed that Agricultural value added is the most influential variables.

\section{Bayesian Network Model for EPI}

In this section, we assessed risk of agri-environmental indicators on Environmental Performance Index (EPI).In table 14, is shown impact of agrienvironmental indicators on EPI.It should be noted we analysis senario $\mathrm{N}_{2} \mathrm{O}$ and $\mathrm{CH}_{4}$ emission impact on EPI that is used for calculate EPI. Also, we investigated senario Agricultural value added impact on EPI.In figures12-13 is shown the prior probability distribution of variables in Bayesian network for Eu and ME countries. 
In Tables 9-10, is shown The results of $\mathrm{N} 2 \mathrm{O}$ and $\mathrm{CH}_{4}$ emissions impact scenario on EPI in the EU and ME countries.

Table 9 The results of posterior probability distribution EPI in the Eu and Middle East countries, 2018

\begin{tabular}{|c|c|c|}
\hline Variable & EU countries & \\
\hline $\mathrm{N}_{2} \mathrm{O}$ emissions & $\mathrm{CH}_{4}$ emissions & \\
\hline LOW & High & LOW High \\
\hline $100 \%$ & - & $100 \%-$ \\
\hline EPI & Low & $32.9 \%$ \\
\hline High & $67.1 \%$ & \\
\hline
\end{tabular}

Table 10 The results of posterior probability distribution (\%) EPI in the Eu and Middle East countries, 2018

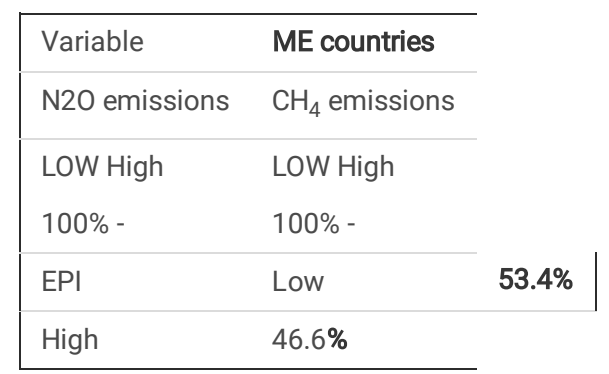

According to table 9, in Eu countries when $\mathrm{N} 2 \mathrm{O}$ and $\mathrm{CH} 4$ emissions decrease EPI with high probability $67.1 \%$ increases. This issue indicates this countries is improved agricultural practices and pesticides and fertilizer use in agricultural sector. Therefore, resulted pollution from pesticides and fertilizer use is reduced. In ME countries, when $\mathrm{N} 2 \mathrm{O}$ and $\mathrm{CH} 4$ emissions decrease EPI with high probability $53.4 \%$ decreases. Therefore these countries have not been successful in improving the environmental performance index and sustainable development objectives.

Table 11 The results of posterior probability distribution (\%) EPI in Eu and Middle Eastcountries, 2017.

\begin{tabular}{|lll|}
\hline Variable & EU countries \\
\cline { 1 - 2 } Agricultural value added & \\
\cline { 1 - 2 } LOW & High & \\
$100 \%$ & - & $40.7 \%$ \\
\hline EPI & Low & \\
\hline High & $\mathbf{5 9 . 3 \%}$ & \\
\hline
\end{tabular}

Table 12 Results of posterior probability distribution EPI in Eu and Middle Eastcountries, 2017.

\begin{tabular}{|c|c|c|}
\hline Variable & ME countries & \\
\hline Agricultural value added & & \\
\hline LOW & High & \\
\hline $100 \%$ & - & \\
\hline EPI & Low & $56.3 \%$ \\
\hline High & $43.7 \%$ & \\
\hline
\end{tabular}

In tables 11-12 is shown agricultural value added impacts on EPI in Eu and ME countries. The results indicate in EU countries when agricultural value added increase EPI with high probability 59.3\% increases. But In ME countries with increase agricultural value added, EPI with high probability $56.3 \%$ decreases. Therefore, agricultural growth in ME countries could not improve EPI. Agricultural play an important role in majority of the Middle East countries economic, But policymakers have not paid much attention to this sector.

In figures 14, is shown sensitivity analsis. According to figure 14, in EU countries N2O emissions is highest variable on EPI and in ME countries agricultural value added is highest variable on EPI.

\section{Conclusion}


According it is important to assessment the relationship between agri-environmental and economic indicators that are sustainable development dimensional. In present study, a Bayesian network model was applied to investigate the relation between agri-economic-environmental indicators in the EU countries compared to middle East countries. In first, we showed relations between variables of model based on expert interview and previous studies. Secondly, we applied K-means cluster analysis for classify of variables values in EU and Middle East countries. Thirdly, we analysis the scenarios results of changing Agriculture area certified organic, conservation agricultural, Balance per hectare in in EU and Middle East countries. Our findings showed When Agriculture area certified organic and conservation agricultural area be at high state in EU countries, Land Productivity is medium with highest probability 33.6\%. Therefore, we predicted with increasing Agriculture area certified organic and conservation agricultural area, a probability, 100\%, Land Productivity can be increased with a probability $33.6 \%$ in EU Countries. Also, the results indicated with increasing Agriculture area certified organic and conservation agricultural area, a probability, $100 \%$, Land Productivity and agricultural value added can be increased with a probability $56.8 \%$ and $57.5 \%$ in the Middle East Countries, respectively. This indicates that organic farming can improvement food security. Organic farming should be considered as one Strategies for community development and sustainable food systems for Improve food security. The results of sensitivity analysis showed in EU countries Labor Productivity and land productivity has highest impact on agricultural value added and in Middle East Countries land productivity has highest impact on agricultural value added.Also, The results provided to decrease pesticiede, Nutrient nitrogen, Nutrient phosphate, and Nutrient potash consumption, can improve Environmental Performance Index in the Eu and Middle East countries. The Middle East region faces a wide array of environmental stresses that include water scarcit and air pollution. Therefore, Middle East countries should apply different approaches to reforming agricultural policy in regard with sustainable development objectives.

The results suggest that Agriculture area certified organic creates more added value in agricultural sector. Organic farming lead to minimal use of fertilizers and pesticides, however, it can be made lower input costs. Also, Organic farming can increase land productivity that has highest impact on agricultural value added. Also, The EU and Middle East countries should seek to manage and control agrichemicals use in agricultural sector. Pollution emission of pesticides and fertilizer use significantly decrease the level of environmental performance index.

In summary, based on the results provided from this study, Bayesian networks could be applied in further research for investigating agri-environmental impacts and environmental management modelling.

\section{Declarations}

\section{Authors' contributions}

SN analyzed and interpreted the meteorological and was a major contributor in writing the manuscript. AF wrote the methodology.All authors read and approved the final manuscript.

\section{Funding}

This study was supported by no organization or person.

\section{Data availability}

The datasets used during the current study are available from the corresponding author on reasonable request.

\section{Compliance with ethical standards}

Competing interests The authors declare that they have no competing interests.

Ethical approval Not applicable.

Consent to participate Not applicable.

Consent to publish Not applicable.

\section{References}

Alcamo J, Henrichs T, Rösch T (2000) World water in 2025-global modeling and scenario analysis for the World Commission on Water for the 21st Century, Kassel World Water Series, Univ. of Kassel, Kassel, Germany.

Ali Shah, S. A and Longsheng, C )2020( New environmental performance index for measuring sector-wise environmental performance: a case study of major economic sectors in Pakistan. Environmental Science and Pollution Research. https://doi.org/10.1007/s11356-020-10145-z

Arnaldo Valdés R, Liang Cheng S, Gómez Comendador V, Sáez Nieto F (2018) Application of Bayesian Networks and Information Theory to Estimate the Occurrence of Mid-Air Collisions Based on Accident Precursors. Entropy.20, 969.

Batary P, V. Dicks L, Kleijn D, J.Sutherland W (2015) The role agri-environmental shemes in conservation and environmental management. Conservation Biology 29(4): 1006-1016. 
Carpani M, Giupponi C (2010) Construction of a Bayesian Network for the Assessment of Agri-Environmental Measures - The Case Study of the Venice Lagoon Watershed. Ital. J. Agron 3:265-274.

Carriger J.F, Parker R.A (2021) Conceptual Bayesian networks for contaminated site ecological risk assessment and remediation support. Journal of Environmental Management 278: 1-11.

Chai J, Shi, H, Lu, Q, Hu Y (2020) Quantifying and predicting the Water-Energy-Food-Economy-Society-Environment Nexus based on Bayesian networks - a case study of China. Journal of Cleaner production 256:1-27.

Chakrabarty T, Akter A, Saifullah A.S.M, Sheikh Md.S, Bhowmick A.C (2014). Use of fertilizer and pesticide for crop production in agrarian area of Tangail District Bangladesh. Environ. Ecol. Res 2 (6): 253-261.

Dkhili, H. (2019). Environmental Performance and Economic Growth in Middle East and North Africa Countries. Journal of Health \& Pollution, 9(24):1-9.

Falkenmark M. J, Lundqvist C, Widstrand C (1989) Macro-scale water scarcity requires micro-scale approaches, Nat. Resour. Forum13:258-267.

Food and agricultural Organization of the United Nations )2011(The state of the world's land and water resources for food and agricultural- managing systems at risk ( $1^{\text {st }}$ ed). Rome and Earthscan, London.

Grotkiewicz K (2017) ANALYSIS OF ECONOMIC AND AGRICULTURAL INDICATORS UNDEr SUSTAINABLE AGRICULTURE CONDITIONS WITH THE USE OF BAYESIAN MODELLING. Technical Sciences 20 (3):209-225.

High Level Panel of Experts on Food Security and Nutrition (HLPE/FSN) (2016) Sustainable agricultural development for food security and nutrition: what roles for livestock? A report by the High Level Panel of Experts on Food Security and Nutrition of the Committee on World Food Security, Rome.144 pp. Available at:http://www.fao.org/fileadmin/user_upload/hlpe/hlpe_documents/HLPE_Report

Jafari Samimi A, Esmaeili Erami N $\square$ Mehnatfar Y )2010 (Environmental Performance Index and Economic Growth: evidence from some Developing Countries. Australian Journal of Basic and Applied Sciences 4(8): 3098-3102.

Kaikkonen L, Parviainen T, Rahikainen M, Uusitalo L, Lehikoinen A. 2020. Bayesian Networks in Environmental Risk Assessment: A Review.Integrated Environmental Assessment and Management 17(5):1-17 https://doi.org/10.1002/ieam.4332.

Korb K. B, A. E. Nicholson A.E (2011) Bayesian artificial intelligence. Chapman \& Hall/CRC, London, UK.

Levontin P, Kulmala S, Haapasaari P, Kuikka S (2011) Integration of biological, economic, and sociological knowledge by Bayesian belief networks: the interdisciplinary evaluation of potential management plans for Baltic salmon. ICES J Mar Sci 68(3):632-638

Li, S., Gong, Q ., Yang, S. 2019. Analysis of the Agricultural Economy and Agricultural Pollution Using the Decoupling Index in Chengdu, China.International Journal of Environmental Research and Public Health. 16,1-11.

Liu J, Yang H, Gosllng S.N, Kummu M, florke M, Pfister S, Hanasaki N, Wada Y, Zhang X, Zheng C, Alcamo J, Oki T (2017). Water scarcity assessments in the past, present, and future. AGUPUbLICATIONS Earth's Future 5:545-559.

Maleki A (2018) Environmental Pollution in The Middle East.Strategics Studies of Public Policy (Strategic Studies of Globalization Journal) 8(27): 349-359.

Mamitimin Y, Feike T, Doluschitz R (2015) Bayesian network modeling to improve water pricing practices in northwest China. Water 7(10): 5617-5637.

Mitchell TM (1997). Machine Learning. McGraw-Hill.

Mohammadian F, Yazdani S, Fehresti-sani M (2020) The Role of Diversity in Improving Environmental Indicators: A Case Study in Mahidasht Plain, Iran. International Journal of Environmental Research 1-14 , doi.org/10.1007/s41742-020-00288-9.

Muller A, Schader C, El-Hage Scialabba N, Judith Brüggemann J , Isensee,A. , Erb K.H, Smith P,Peter Klocke P, Leiber F, Stolz., F, Niggli U (2017) Strategies for feeding the world more sustainably with organic agriculture. NATURE COMMUNICATIONS | DOI: 10.1038/s41467-017-01410-w

Pretty J (2008) Agricultural sustainability: Concepts, principles and evidence. Philos. Trans. R. Soc. Lond. B Biol. Sci 363: $447-465$.

Punith Kumar L.M, Indria M (2017). Trends in Fertilizer Consumption and Food Grain Production in India: A Co-Integration Analysis. SDMIMD Journal of Management. 2:45-50.

Radermacher, W. 2009. Sustainable development in the European Union. monitoring report of the EU sustainable development strategy.

Russell A, Chalaieny M, Gazdiyeva B, Sara Zhumabayeva S, Kurmanbayeva A, Akhmetov K.K, Mukanov Y, McCann M, Ali M, Tucker A, Vitolo C, Althonayan A (2018) A Spatial Survey of Environmental Indicators for Kazakhstan: An Examination of Current Conditions and Future Needs. International Journal of Environmental Researh 12:735-748.

Page $10 / 16$ 
Safarelizadeh E, Hosseinzadeh R,Akbari, M (2017) The Analysis of the Relative Performance of the Middle East in Terms of Sustainable Development Indices.Journal of Regional Planning 8(29), 1-11.

Sharma N, Singhvi R (2017). Effects of chemical fertilizers and pesticides on human health and environment: a review. Int. J. Agric. Environ. Biotechnol 10 (6): 675-679.

Sule I, Khan F, Butt S, Yang M (2018). Kick control reliability analysis of managed pressure drilling operation. J Loss Prev Process Ind 52:7-20.

Sulewski P, Kloczho- Gajewska Sroka W. (2018). Relations between Environmental, Economic and Social Dimensions of Farms' Sustainability.sustainability 10:1-23.

United Nations (2015). Population Pyramids of the World from 1950 to 2100 . World Population Prospects. Retrieved from. https://un.org

United Nations. 2020. Policy Brief: The Impact of COVID-19 on Food Security and Nutrition.

United Nations. Resolution Adopted by the General Assembly on 25 September 2015. Transforming Our World: The 2030 Agenda for Sustainable Development; Seventieth Session; Distr. General 21; United Nations: New York, NY, USA, 2015.

Vikari A, Hietala R, Huusela-Veistola E, HyvönenT (2007). Evaluating agri-environmental indicators (AEls)-Use and limitations of international indicators at national level. Ecological Indicators 7(1): 150-163.

Volkov, A., Morkunas, M., Balezentis, T \& Sapolaite, V. (2020). Economic and Environmental Performance of the Agricultural Sectors of the Selected EU Countries. Sustainability, 12:1-17.

Vörösmarty C. J, Green P, Salisbury J, LammersR. B (2000). Global water resources: Vulnerability from climate change and population growth, Science 28: $284-288$.

Widayati T, Waridin W, Mafruhah, L (2019) Between Environmental Performance and Agricultural Productivity: Assessing the Convergence and Divergence of Demand-Driven Agricultural Extension," International Journal of Energy Economics and Policy, Econjournals, 9(4): $158-165$.

World Health Organization (WHO); Food and Agriculture Organization of the United Nations (FAO). Organically Produced Foods. Available online: http://ftp.fao.org/docrep/fao/010/a1385e/a1385e00.pdf (accessed on 14 October 2015).

Zarandi Motasadi, S and Bebaran, S. 2009.Strategies of the environmental sector to achieve the goals of the 20-year vision document of the country. Strategy Quarterly,48:101-122.

\section{Figures}

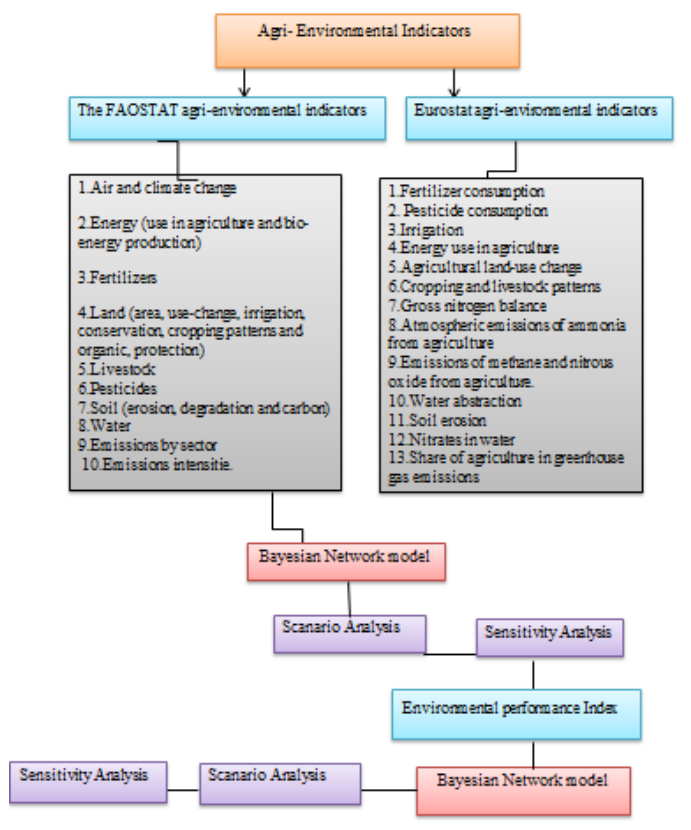

Figure 1

Flowchart of the present Study for predicting agri-economics indicators using Bayesian Network 


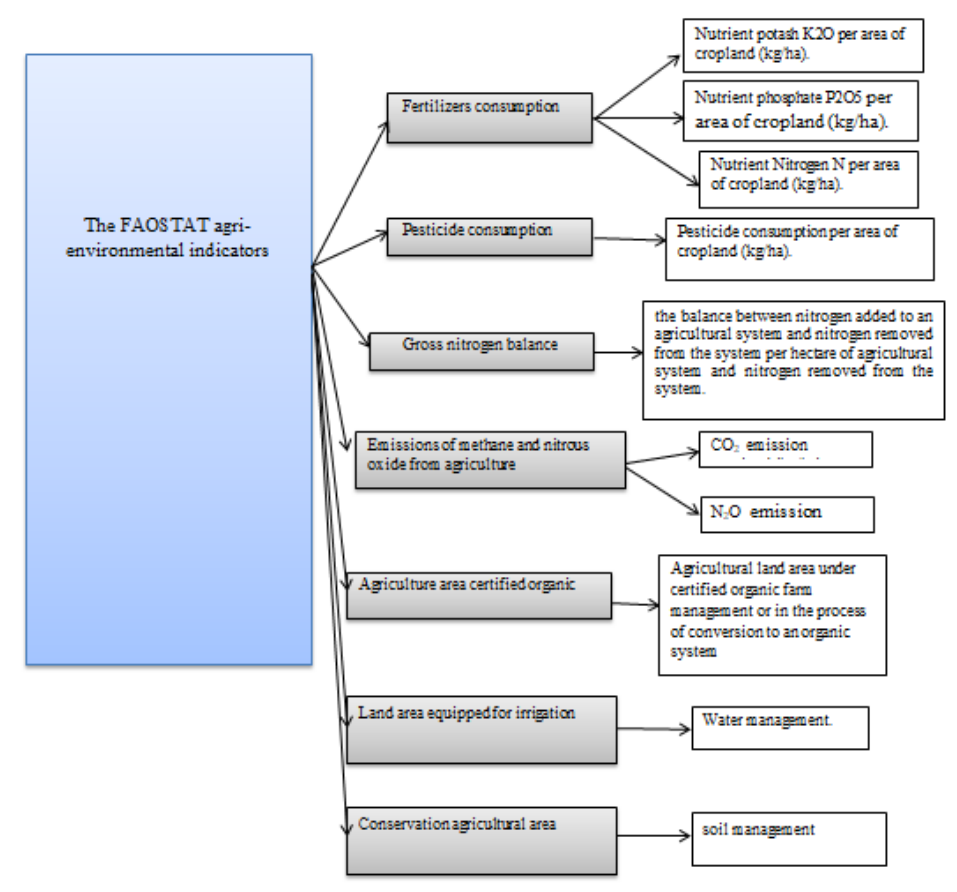

Figure 2

Flowchart of the present Study for FAOSTAT agri-environmental indicators, 2018

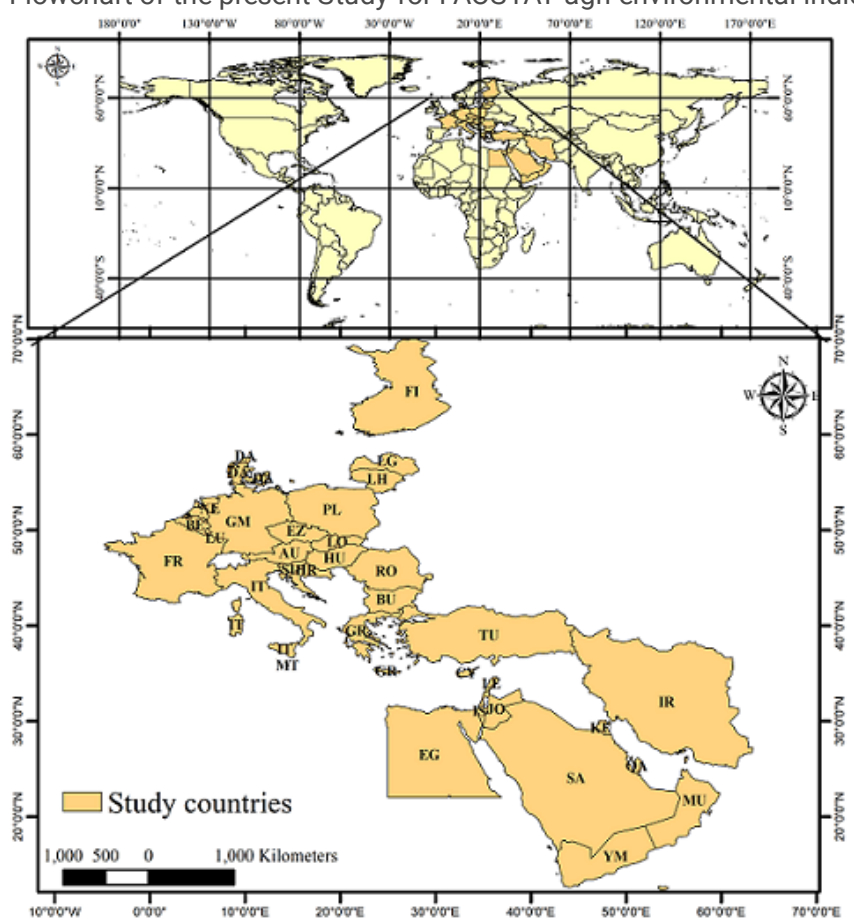

Figure 3

Geographical location of the study region. Note: The designations employed and the presentation of the material on this map do not imply the expression of any opinion whatsoever on the part of Research Square concerning the legal status of any country, territory, city or area or of its authorities, or concerning the delimitation of its frontiers or boundaries. This map has been provided by the authors. 


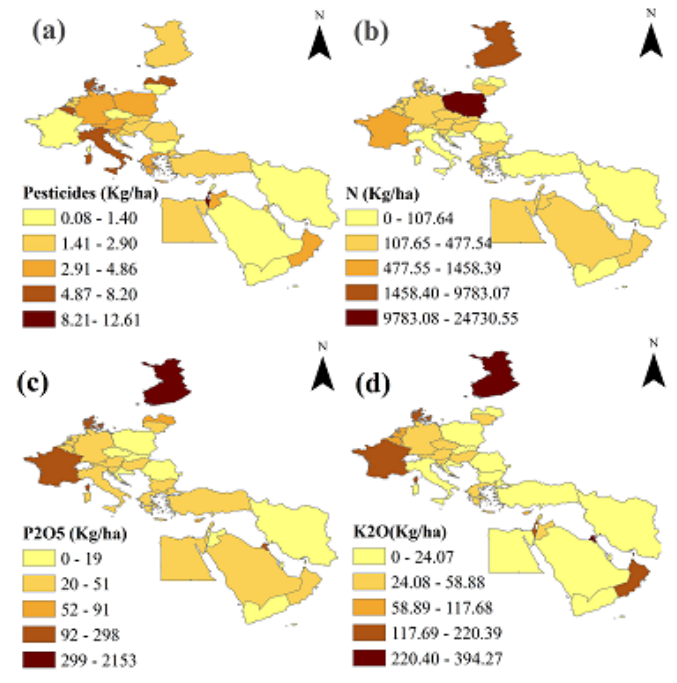

Figure 4

Consumption of pesticides, N, P2O5 and K2O, respectively. Note: The designations employed and the presentation of the material on this map do not imply the expression of any opinion whatsoever on the part of Research Square concerning the legal status of any country, territory, city or area or of its authorities, or concerning the delimitation of its frontiers or boundaries. This map has been provided by the authors.

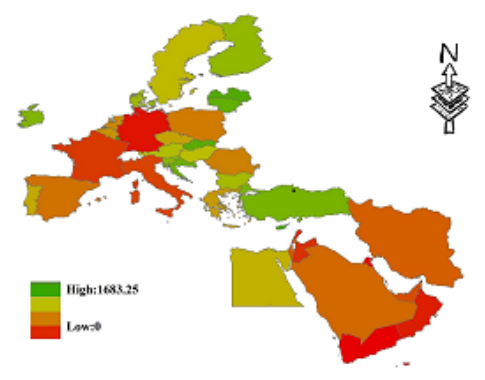

\section{Figure 5}

Agriculture area certified organic. Note: The designations employed and the presentation of the material on this map do not imply the expression of any opinion whatsoever on the part of Research Square concerning the legal status of any country, territory, city or area or of its authorities, or concerning the delimitation of its frontiers or boundaries. This map has been provided by the authors.

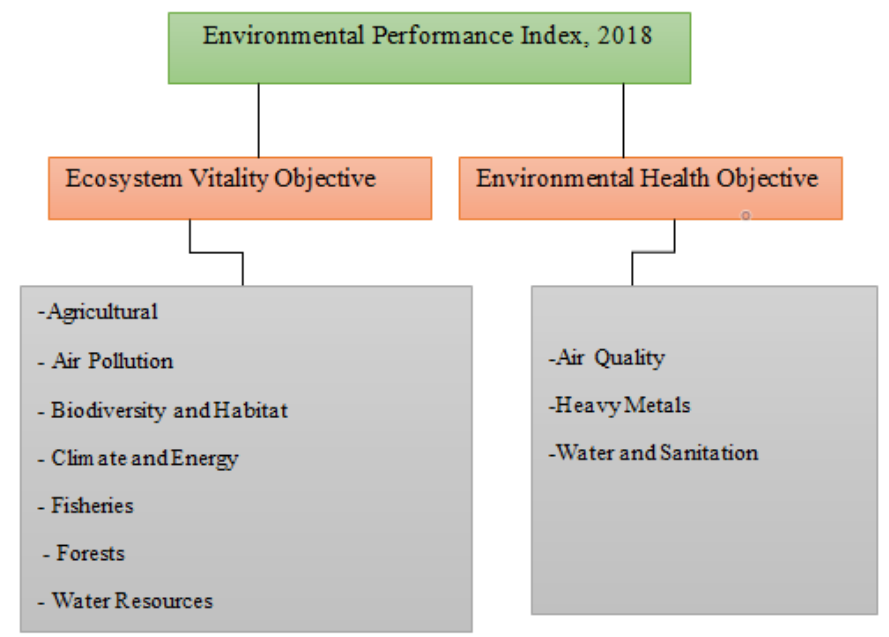

\section{Figure 6}

Environmental performance index, Yale University, 2018 


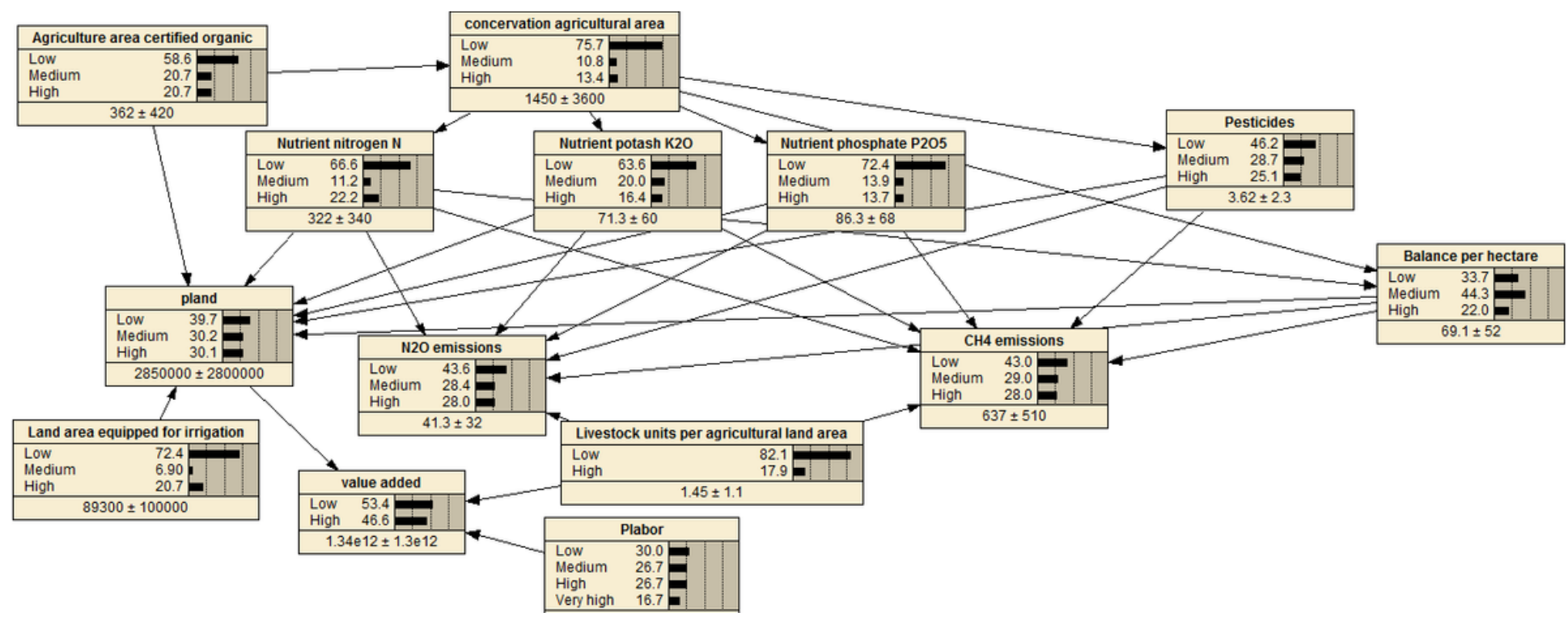

Figure 8

Bayesian network with the probability distribution of variables, EU countries

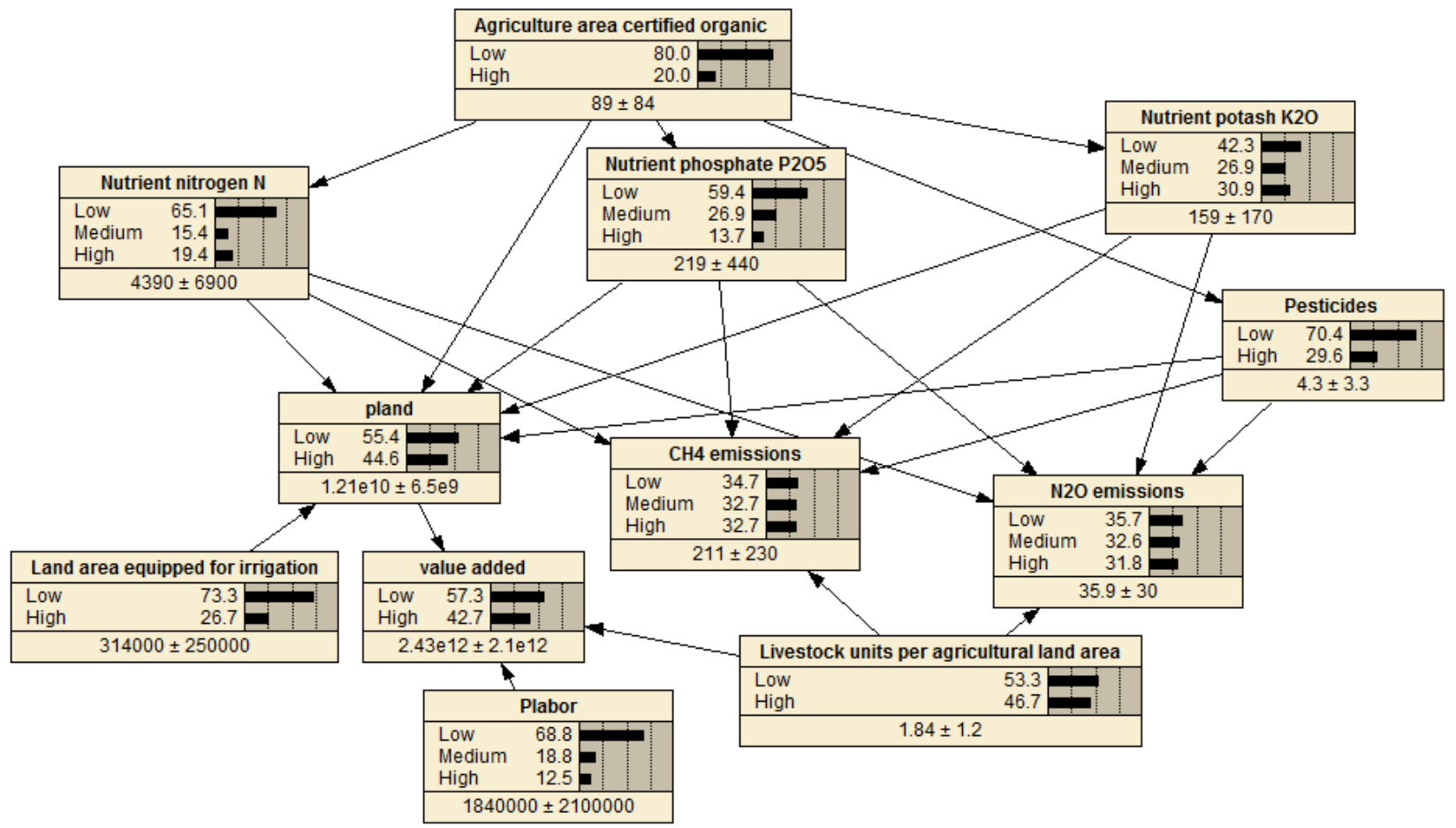

Figure 9

Bayesian network with the probability distribution of variables, Middle East countries
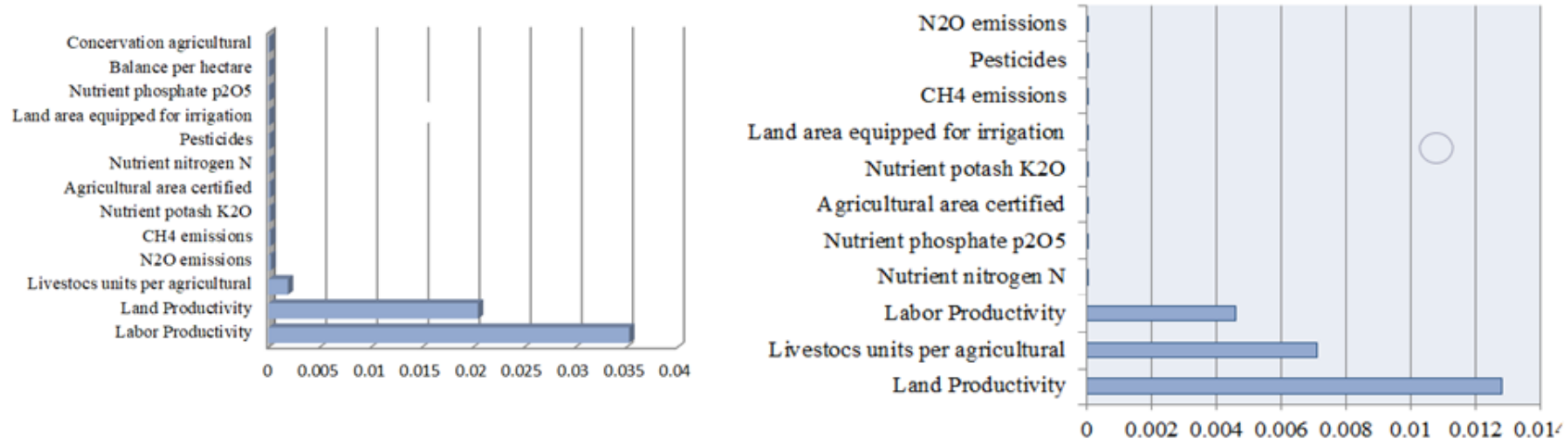


\section{Figure 10}

The results of the sensitivity analysis of BN for agricultural value added, EU and ME, respectively.
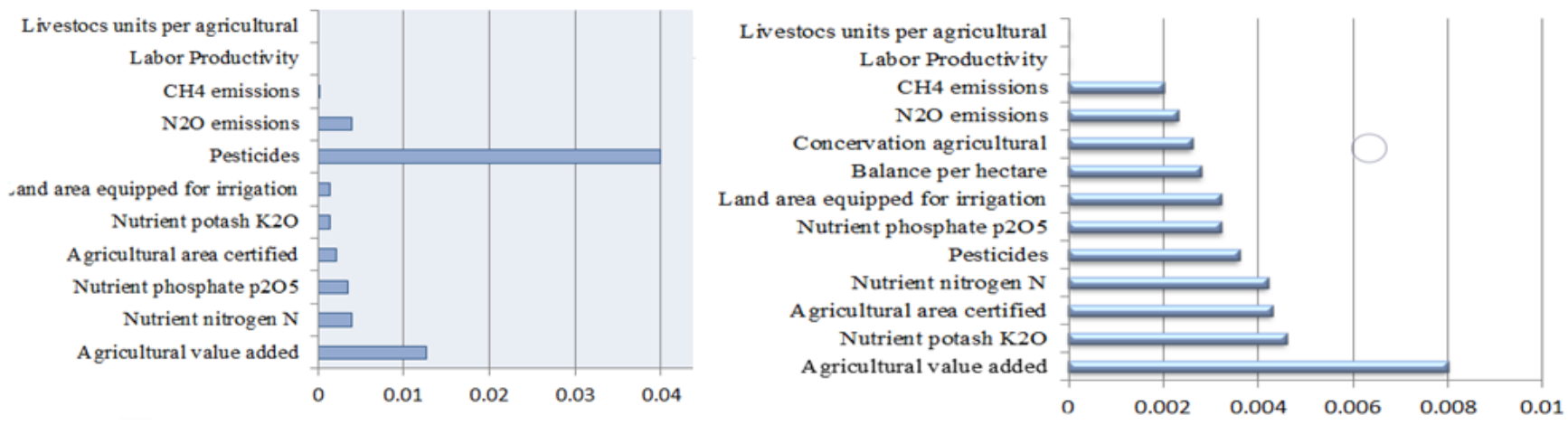

\section{Figure 11}

The results of the sensitivity analysis of BN for land productivity, EU and ME, respectively.

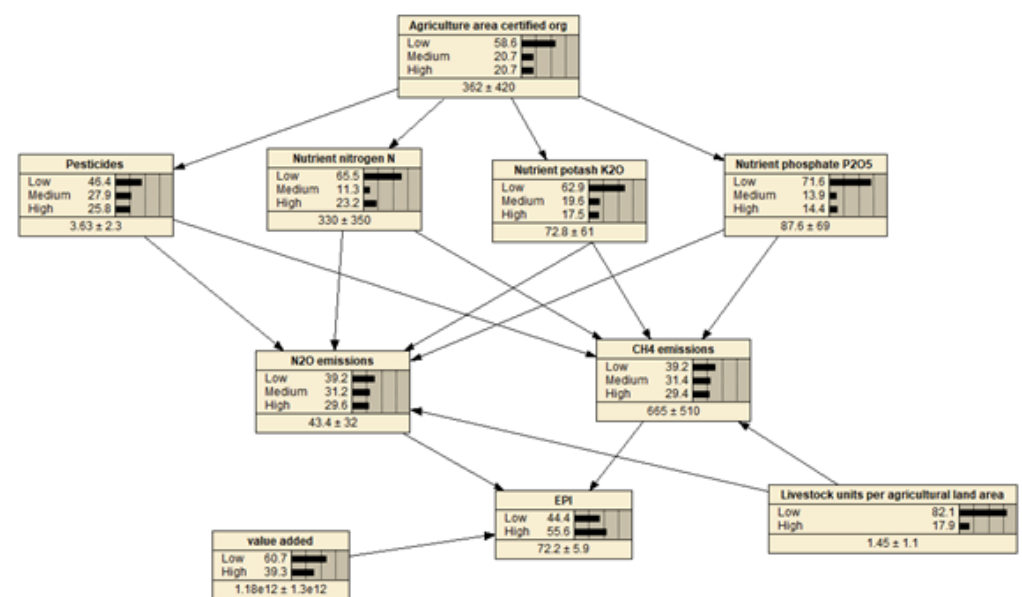

Figure 12

Bayesian network with the probability distribution of variables, Eu countries 


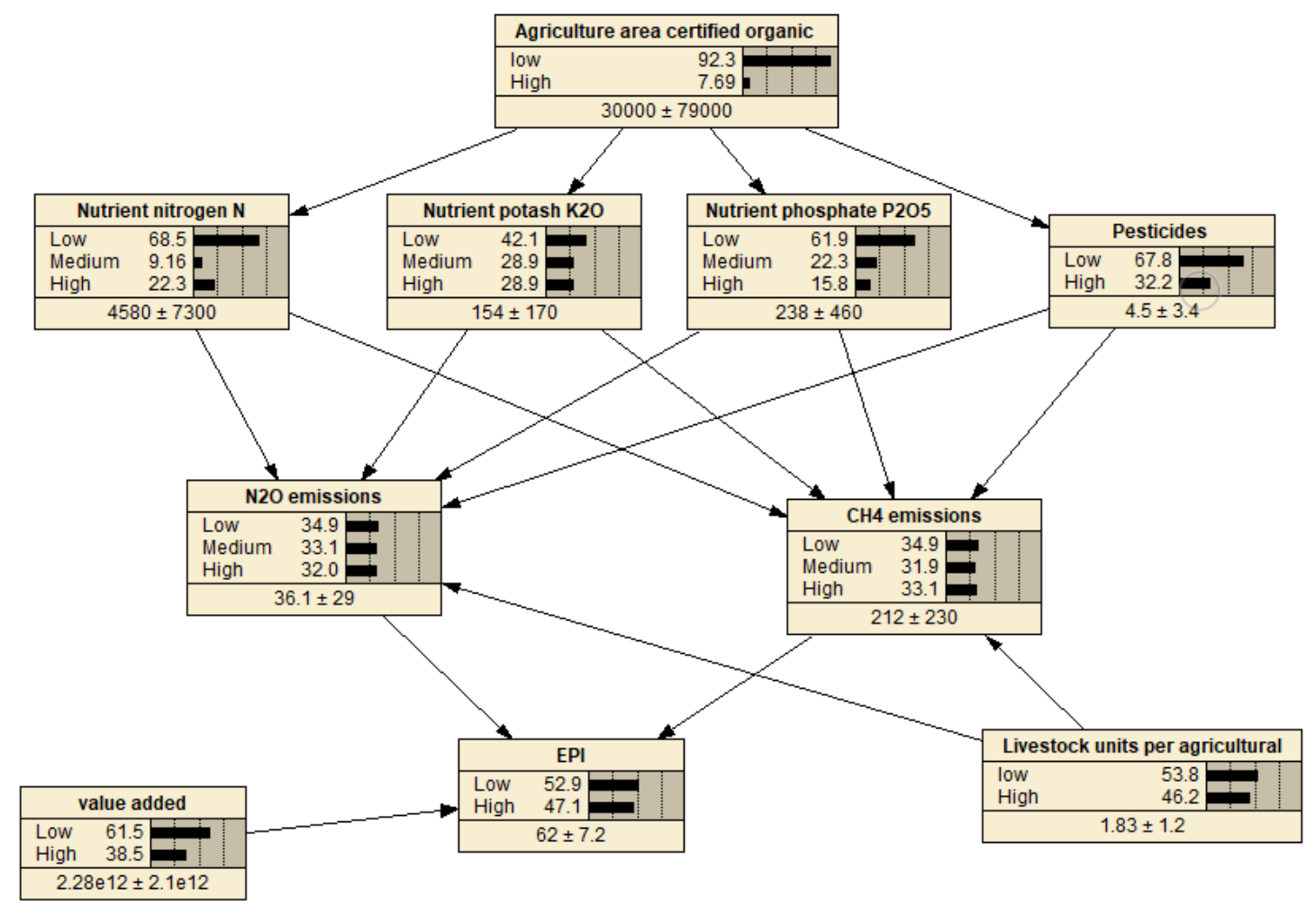

\section{Figure 13}

Bayesian network with the probability distribution of variables, Middle East countries
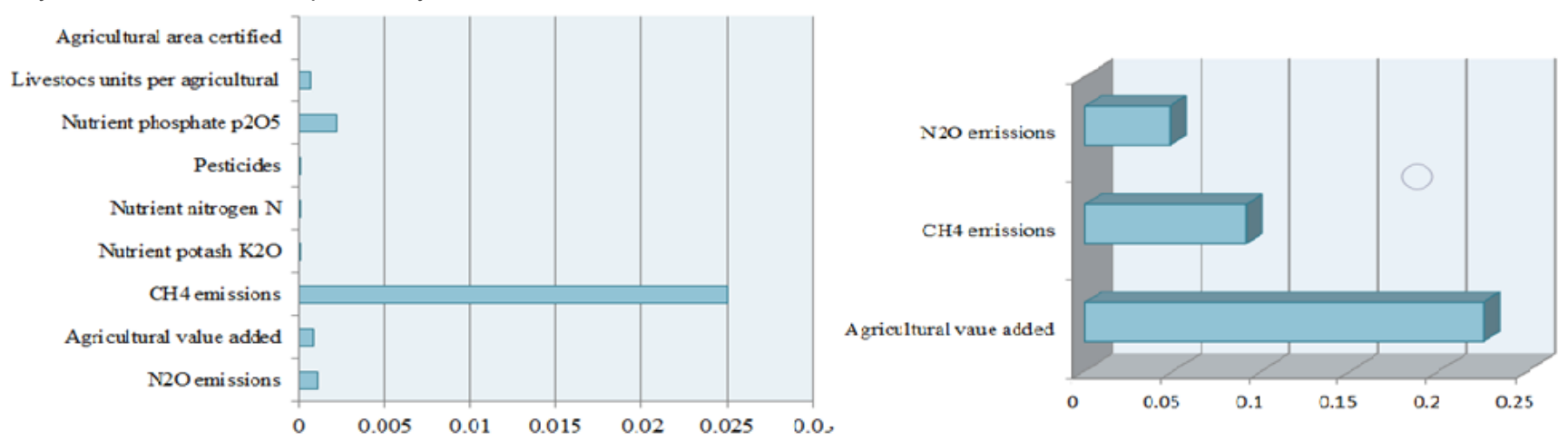

\section{Figure 14}

Bayesian network with the probability distribution of variables, EU and ME, respectively. 